Article

\title{
Efficient Degradation of Aqueous Carbamazepine by Bismuth Oxybromide-Activated Peroxide Oxidation
}

\author{
Tuqiao Zhang ${ }^{1}$, Shipeng Chu ${ }^{1}$, Jian Li ${ }^{1}$, Lili Wang ${ }^{2}$, Rong Chen ${ }^{1}$, Yu Shao ${ }^{1}$, Xiaowei Liu ${ }^{1,3, *}$ \\ and Miaomiao Ye ${ }^{1, *}$ \\ 1 Institute of Municipal Engineering, College of Civil Engineering and Architecture, Zhejiang University, \\ Hangzhou 310058, China; 0012688@zju.edu.cn (T.Z.); chushipeng@zju.edu.cn (S.C.); xero@zju.edu.cn (J.L.); \\ 21512060@zju.edu.cn (R.C.); shaoyu1979@zju.edu.cn (Y.S.) \\ 2 Environmental Engineering, Jiyang College, Zhejiang A \& F University, Zhuji 311800, China; liilive@163.com \\ 3 Institute of Port, Coastal and Offshore Engineering, Ocean College, Zhejiang University, \\ Hangzhou 310058, China \\ * $\quad$ Correspondence: liuxiaowei@zju.edu.cn (X.L.); yemiao008@zju.edu.cn (M.Y.); Tel.: +86-571-8820-8721 (X.L.)
}

Received: 28 September 2017; Accepted: 18 October 2017; Published: 26 October 2017

\begin{abstract}
Bismuth oxyhalide, usually employed as a photocatalyst, has not been tested as an activator of peroxide for water purification. This work explores the potential application of bismuth oxyhalide ( $\mathrm{BiOX}, \mathrm{X}=\mathrm{Cl}, \mathrm{Br}$, I)-activated peroxide $\left(\mathrm{H}_{2} \mathrm{O}_{2}\right.$; peroxymonosulfate (PMS) and peroxydisulfate) systems for the degradation of carbamazepine (CBZ) in water destined for drinking water. $\mathrm{BiOBr}$ showed the highest activity toward the peroxides investigated, especially toward PMS. The most efficient combination, BiOBr/PMS, was selected to further research predominant species responsible for CBZ degradation and toxicity of transformation products. With repeated use of $\mathrm{BiOBr}$, low bismuth-leaching and subtle changes in crystallinity and activity were observed. CBZ degradation was primarily (67.3\%) attributable to attack by sulfate radical. Toxicity test and identification of the oxidation products indicated some toxic intermediates may be produced. A possible degradation pathway is proposed. Besides substitution of the hydroxyl groups on the surface of the catalyst particles, PMS's complexation with the lattice Bi(III) through ion exchange with interlayer bromide ion was involved in the decomposition of $\mathrm{PMS}$. The $\mathrm{Bi}(\mathrm{III})-\mathrm{Bi}(\mathrm{V})-\mathrm{Bi}(\mathrm{III})$ redox cycle contributed to the efficient generation of sulfate radicals from the PMS. Our findings provide a simple and efficient process to produce powerful radicals from PMS for refractory pollutant removal.
\end{abstract}

Keywords: advanced oxidation technologies; bismuth oxybromide; carbamazepine; peroxide; toxicity

\section{Introduction}

Carbamazepine (CBZ) is a typical pharmaceutically-active compound widely used to control epilepsy and neuropathic pain [1]. Due to its improper disposal after use, CBZ is frequently detected in wastewater treatment plant effluents [2,3], surface water [4] and even drinking water [5] at nanogramto milligram-per-liter concentrations. CBZ's persistence in the ecosystem has urged researchers to investigate effective treatment technologies. Researchers have previously reported a general removal rate of CBZ below $10 \%$ for conventional biological wastewater treatment processes [6]. Even a popular membrane bioreactor removes less than 20\% [1,7-9]. Conventional water-treatment processes cannot sufficiently eliminate CBZ $[10,11]$. More-efficient treatment technologies are urgently needed.

Advanced oxidation technologies (AOTs) have been extensively explored as an alternative solution for degrading and detoxifying bio-recalcitrant and toxic organic pollutants in water. Among AOTs, semiconductor photocatalytic oxidation, which can use UV and visible light energy, has generated much interest [12]. Recently, a relatively new and promising photocatalytic material-bismuth oxyhalide (BiOX, $\mathrm{X}=\mathrm{Cl}, \mathrm{Br}, \mathrm{I}$ ) - has drawn considerable attention. The bandgap energies for $\mathrm{BiOCl}$, 
$\mathrm{BiOBr}$ and $\mathrm{BiOI}$ are about 3.2, 2.7 and $1.7 \mathrm{eV}$ [13], respectively. Thus, BiOX can be driven by UV/visible light irradiation to degrade pollutants. For liquid-phase photocatalytic BiOX processes, hydroxyl radicals (HO.), superoxide radicals and photoinduced holes have been considered to play important roles [14]. Notably, rare effort has been devoted to producing reactive radicals such as HO. through BiOX-catalyzed decomposition of radical precursors like peroxides.

It is well established that $\mathrm{BiOX}$ compounds crystallize in layers in which double slabs of halogen atoms are interleaved with $\left[\mathrm{Bi}_{2} \mathrm{O}_{2}\right]$ slabs [13]. Once metal oxides are added into water, dissociative adsorption of water molecules results in the formation of surface hydroxyl groups $(-\mathrm{OH})$ [15]. Peroxides can complex with the metal ions on the surface of metal oxides by replacing part of the surface $-\mathrm{OH}$, generating $\mathrm{HO}$. and $\mathrm{SO}_{4}^{--}$radicals through electron transfer [16]. Therefore, besides acting as a photocatalyst, BiOX may activate peroxides and thus induce the degradation of organic pollutants. A preliminary study in our laboratory has found that $\mathrm{BiOBr}$ is indeed able to activate peroxymonosulfate (PMS). In addition, peroxides are usually applied as scavengers of photoinduced electrons rather than as radical precursors to increase the degradation rate of organic compounds through a semiconductor photocatalytic processes [17]. To date, CBZ degradation by BiOX-induced peroxide activation has not yet been documented.

In this study, the BiOX-enhanced degradation of $\mathrm{CBZ}$ was investigated using peroxide $\left(\mathrm{H}_{2} \mathrm{O}_{2}\right.$, PMS and peroxydisulfate (PS)) addition with clean and natural water. Active species contributing to CBZ degradation were identified and those contributions were quantitatively analyzed. A mechanism for active species formation was proposed. Any changes in the biotoxicity of the reaction mixtures during the degradation process were monitored using Vibrio fisheri bioassays. Finally, the intermediates involved were characterized using high-performance liquid chromatography coupled with mass spectrometry (HPLC-MS) to elucidate the degradation pathway for CBZ.

\section{Results and Discussion}

\subsection{CBZ Degradation}

\subsubsection{Degradation of CBZ under Pure Water Background}

CBZ adsorbed weakly onto the surface of the three types of $\mathrm{BiOX}(\mathrm{X}=\mathrm{Cl}, \mathrm{Br}, \mathrm{I})$ microspheres (Figure 1a), and it was barely oxidized by the peroxides studied $\left(\mathrm{H}_{2} \mathrm{O}_{2}\right.$, PS and PMS) alone without the BiOX catalyst (Figure $1 \mathrm{~b}-\mathrm{d}$ ). The degradation of $\mathrm{CBZ}$ required synergistic action of the peroxides and the BiOX. As shown in Figure $1 b, c$, the combination of BiOX with $\mathrm{H}_{2} \mathrm{O}_{2}$ or PS generated only rather slow CBZ degradation. By contrast, the rate with BiOX and PMS was much better (Figure 1d).

Among the three $\mathrm{BiOX}$ compounds, $\mathrm{BiOBr}$ showed the best degradation effectiveness, exhibiting $100 \%$ degradation of the CBZ in less than $5 \mathrm{~min}$. Such catalytic performance was comparable with that of $\mathrm{CuFe}_{2} \mathrm{O}_{4}$ ferrite catalysts (Figure S3, Supplementary Materials). $\mathrm{BiOBr}$ was much more efficient than $\mathrm{CuFe}_{2} \mathrm{O}_{4}$ as a PMS activator.

The molecular structure of the peroxides and the physicochemical properties of the BiOX are important to the efficiency of peroxide activation by BiOX. The dissociation energy of the peroxide $(\mathrm{O}-\mathrm{O})$ bond in the three peroxides and their ability to bind with BiOX are two key factors. The lower $\mathrm{O}-\mathrm{O}$ bond energy and easier availability of free persulfate ion under neutral $\mathrm{pH}$ compared with $\mathrm{H}_{2} \mathrm{O}_{2}$ (Table 1) explain why either persulfate (PS or PMS) was easier to activate than $\mathrm{H}_{2} \mathrm{O}_{2}$ by the same oxyhalide. The observed performance difference between PS and PMS can be attributed to the asymmetrical structure of PMS (compared with the symmetrical structure of $\mathrm{H}_{2} \mathrm{O}_{2}$ and PS) [18]. 

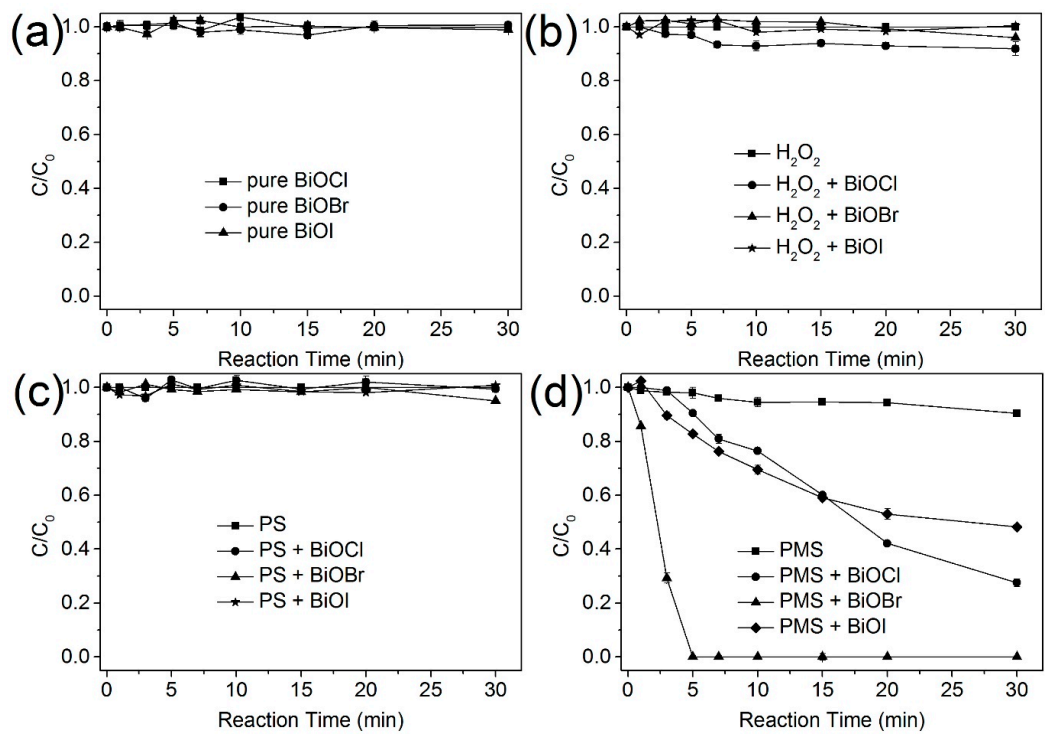

Figure 1. The catalyzed PMS oxidation of CBZ by (a) BiOX, (b) $\mathrm{H}_{2} \mathrm{O}_{2}$, (c) PS and (d) PMS. The initial concentration of CBZ $\left([\mathrm{CBZ}]_{0}\right)=5.0 \mu \mathrm{M},\left[\mathrm{H}_{2} \mathrm{O}_{2}\right]_{0}=[\mathrm{PS}]_{0}=[\mathrm{PMS}]_{0}=4.0 \mathrm{mM},[\mathrm{BiOX}]_{0}=1.0 \mathrm{~g} / \mathrm{L}$, $\mathrm{pH}=7.0, \mathrm{~T}=24^{\circ} \mathrm{C}$.

Table 1. Physicochemical properties of $\mathrm{H}_{2} \mathrm{O}_{2}$, PS and PMS.

\begin{tabular}{ccccc}
\hline & $\begin{array}{c}\text { Chemical } \\
\text { Structure }\end{array}$ & $\begin{array}{c}\text { O-O Bond Energy } \\
\left(\mathbf{E}, \mathbf{k J} \cdot \mathbf{m o l} \mathbf{m}^{-1} \mathbf{)}\right.\end{array}$ & pKa & Ref. \\
\hline $\mathrm{H}_{2} \mathrm{O}_{2}$ & $\mathrm{H}^{-} \mathrm{O}^{-} \mathrm{O}^{-} \mathrm{H}$ & 213.3 & $\mathrm{H}_{2} \mathrm{O}_{2} \rightarrow \mathrm{HO}_{2}^{-}+\mathrm{H}^{+} \mathrm{pKa}=11$ & {$[19,20]$} \\
$\mathrm{PS}$ & $\mathrm{O}_{3} \mathrm{~S}^{-} \mathrm{O}^{-} \mathrm{O}^{-} \mathrm{SO}_{3}^{-}$ & 140 & no change in dissociation form $\mathrm{pH}>3$ & {$[19]$} \\
$\mathrm{PMS}$ & $\mathrm{H}^{-} \mathrm{O}^{-} \mathrm{O}^{-} \mathrm{SO}_{3}^{-}$ & $140<\mathrm{E}_{\mathrm{PMS}}<213.3$ & $\mathrm{HSO}_{5}^{-} \rightarrow \mathrm{SO}_{5}^{2-}+\mathrm{H}^{+} \mathrm{pKa}=9.4$ & {$[16,19]$} \\
\hline
\end{tabular}

The structure and surface chemistry of the BiOX would of course be expected to affect its activation of peroxides and thus the overall degradation effectiveness. Brunauer Emmett Teller (BET) surface area is one important determinant. The average pore size, particle size and $\mathrm{pH}_{\mathrm{pzc}}$ were also influential (Table S1, Supplementary Materials). One can find correlation between degradation effectiveness of CBZ and BET surface area of BiOX (Figure S4, Supplementary Materials). The specific surface area of $\mathrm{BiOBr}$ was $10 \%$ larger than that of $\mathrm{BiOCl}$. That corresponds with more accessible active sites, such as surface hydroxyl groups and $\mathrm{Bi}(\mathrm{III})$ ion, which may explain the superior activation with $\mathrm{BiOBr}$. The BiOI had a much-larger specific surface area than the $\mathrm{BiOBr}$, but its activation performance was poorer. That may have reflected the impact of halide released through BiOX hydrolysis (Equation (1), [21]) and ion exchange (Equations (2) and (3), [14]). Interfacial reactions may shed some light on this interesting phenomenon.

$$
\begin{gathered}
\operatorname{BiOX}(X=\mathrm{Cl}, \mathrm{Br}, \mathrm{I})+\mathrm{H}_{2} \mathrm{O} \stackrel{\text { hydrolysis }}{\longrightarrow} \mathrm{BiO}^{+}--\mathrm{OH}+\mathrm{X}^{-}+\mathrm{H}^{+} \\
\mathrm{BiOX}(\mathrm{X}=\mathrm{Cl}, \mathrm{Br}, \mathrm{I})+\mathrm{HSO}_{5}^{-} \stackrel{\text { ion exchange }}{\longrightarrow} \mathrm{BiO}^{+}-\mathrm{HSO}_{5}^{-}+\mathrm{X}^{-} \\
2 \mathrm{BiOX}(\mathrm{X}=\mathrm{Cl}, \mathrm{Br}, \mathrm{I})+\mathrm{S}_{2} \mathrm{O}_{8}^{2-} \stackrel{\text { ion exchange }}{\longrightarrow} 2 \mathrm{BiO}^{+}-\mathrm{S}_{2} \mathrm{O}_{8}^{2-}+2 \mathrm{X}^{-}
\end{gathered}
$$

When $\mathrm{Cl}^{-}, \mathrm{Br}^{-}$or $\mathrm{I}^{-}$is present in an $\mathrm{HO} \cdot$ or $\mathrm{SO}_{4}^{--}$-based process, halogen radicals such as $\mathrm{X} \cdot$ and $\mathrm{X}_{2}^{--}$and nonradical $\mathrm{X}_{3}^{-}, \mathrm{HOX}$ and $\mathrm{X}_{2}$ halogen species with weaker oxidizing power may be formed [22]. Besides its involvement in radical chain reactions with species such as $\mathrm{Cl}^{-}$and $\mathrm{Br}^{-}$[22] and direct reaction with peroxides (Equations (4)-(6)), $\mathrm{I}^{-}$may undergo special reactions with metal ions $\left(\mathrm{Mn}^{\mathrm{n}+}\right)$ when persulfate is present to act as a mediator of electron-transfer reactions (Equations (7)-(10), [23]). 
Such reactions will slow the redox cycling of the surface bismuth ions of the BiOI particles (a color change was observed, as shown in Figure S5 of the Supplementary Materials), which would hinder activation of peroxides, tending to cancel out the enhancement caused by a large specific surface area.

$$
\begin{gathered}
\mathrm{S}_{2} \mathrm{O}_{8}^{2-}+2 \mathrm{I}^{-} \rightarrow \mathrm{I}_{2}+2 \mathrm{SO}_{4}^{2-} k=\sim 10^{4} \mathrm{M}^{-1} \cdot \mathrm{s}^{-1} \\
\mathrm{HSO}_{5}^{-}+2 \mathrm{I}^{-}+\mathrm{H}^{+} \rightarrow \mathrm{I}_{2}+\mathrm{SO}_{4}^{2-}+\mathrm{H}_{2} \mathrm{O} \text { slow } \\
\mathrm{H}_{2} \mathrm{O}_{2}+2 \mathrm{I}^{-} \rightarrow \mathrm{I}_{2}+2 \mathrm{OH}^{-} \text {slow } \\
\mathrm{S}_{2} \mathrm{O}_{8}^{2-}+\mathrm{M}^{\mathrm{n}+} \rightarrow \mathrm{S}_{2} \mathrm{O}_{8} \mathrm{M}^{\mathrm{n}-2} \\
\mathrm{~S}_{2} \mathrm{O}_{8} \mathrm{M}^{\mathrm{n}-2}+\mathrm{I}^{-} \rightarrow \mathrm{I}^{+}+\mathrm{M}^{\mathrm{n}+}+2 \mathrm{SO}_{4}^{2-} \\
\mathrm{I}^{+}+\mathrm{I}^{-} \rightarrow \mathrm{I}_{2} \\
\mathrm{I}_{2}+\mathrm{H}_{2} \mathrm{O} \rightarrow \mathrm{I}^{-}+\mathrm{HIO}+\mathrm{H}^{+}
\end{gathered}
$$

For convenience, the system PMS with $\mathrm{BiOBr}$, which was the most-effective combination of a peroxide and a BiOX, was used in the subsequent stability tests, kinetics studies, investigation of the effects of water quality parameters and elucidation of the CBZ degradation pathway.

\subsubsection{Degradation of CBZ under Actual Water Background}

To examine CBZ degradation in more realistic conditions, effluent of sand filter from a drinking water plant (ESF), and tap water of Hangzhou (TP) and Qizhen Lake (QZL), were collected. Before the reaction, the water samples were pretreated by static deposition and membrane filtration $(0.45 \mu \mathrm{m}$ filter). The water quality parameters of the samples are listed in Table 2 . The $\mathrm{pH}$ values were nearly the same, but the other parameters of the various samples were different. Interestingly, the CBZ degradation differed considerably in the different field samples (Figure 2) and from that observed with the MilliQ water. For the tap water, $10 \mathrm{~min}$ of reaction was required to achieve complete removal of CBZ. However, the reaction time for complete removal was $20 \mathrm{~min}$ when QZL was used, indicating that CBZ degradation was inhibited by some background solutes, presumably inorganic salts and dissolved organic matters (DOM) specific to Qizhen Lake.

Table 2. Water quality of the waters collected from tap water (TP), Qizhen Lake (QZL) and effluent of sand filter (ESF).

\begin{tabular}{ccccccc}
\hline & $\begin{array}{c}\text { DOM } \\
(\mathbf{m g} / \mathbf{L})\end{array}$ & $\begin{array}{c}\text { Bicarbonate } \\
(\mathbf{m g} / \mathbf{L})\end{array}$ & $\begin{array}{c}\mathbf{C l}^{-} \\
(\mathbf{m g} / \mathbf{L})\end{array}$ & $\mathbf{p H}$ & $\begin{array}{c}\mathrm{NO}_{3}{ }^{-}-\mathbf{N} \\
(\mathbf{m g} / \mathbf{L})\end{array}$ & $\begin{array}{c}\mathbf{U V}_{\mathbf{2 5 4}} \\
\left(\mathbf{c m}^{-1}\right)\end{array}$ \\
\hline TP & 3.73 & 107.06 & 3.43 & 7.84 & 0.24 & 3.38 \\
QZL & 6.61 & 97.95 & 2.80 & 7.83 & 0.25 & 4.99 \\
ESF & 3.17 & 100.11 & 2.36 & 7.82 & 0.01 & 3.10 \\
\hline
\end{tabular}

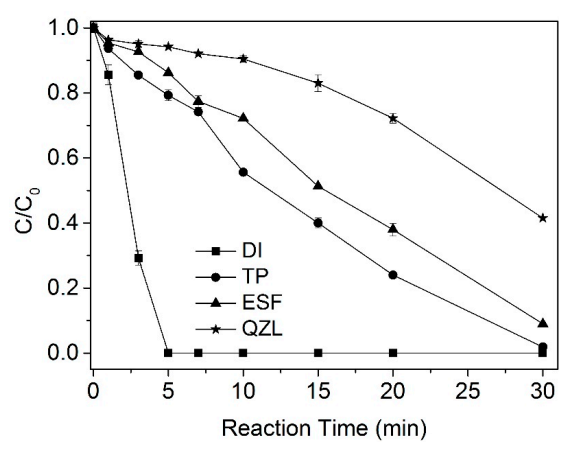

Figure 2. The effects of water matrix on the degradation performance of CBZ. BiOBr dose $0.5 \mathrm{~g} \cdot \mathrm{L}^{-1}$, $[\mathrm{CBZ}]_{0}=5 \mu \mathrm{M},[\mathrm{PMS}]_{0}=4.0 \mathrm{mM}, \mathrm{T}=24^{\circ} \mathrm{C}$. 


\subsection{Stability of BiOBr as a PMS Activator}

To test the durability and stability of the BiOBr catalyst, the particles were reclaimed and reused seven times. The mass-loss during the recycling process was kept within $2.0 \pm 0.5 \%$ (Figure 3 ). The CBZ degradation rate remained almost constant, displaying very stable activation activity for $\mathrm{BiOBr}$ with respect to PMS. After seven reaction cycles the specific surface area of the $\mathrm{BiOBr}$ had not decreased significantly (virgin, $17.6 \mathrm{~m}^{2} \cdot \mathrm{g}^{-1}$; used, $16.8 \mathrm{~m}^{2} \cdot \mathrm{g}^{-1}$ ) (data not shown). In addition, the crystallinity of the $\mathrm{BiOBr}$ as characterized by XRD showed no apparent change after seven reaction cycles (Figure S6, Supplementary Materials). Moreover, any bismuth ion leaching during the degradation process was found to be minor, not exceeding $120 \mu \mathrm{g}$ of bismuth ion per gram of BiOBr over 55 min of reaction time (Figure 4). These leaching bismuth ions may result from interaction of non-lattice surface Bi with PMS, given that $\mathrm{BiOBr}$ suspension in the absence of PMS almost did not release bismuth ion, and a subtle change of $\mathrm{BiOBr}$ crystallinity was observed during repeated use. Generally, this $\mathrm{BiOBr}$ catalyst was very stable.

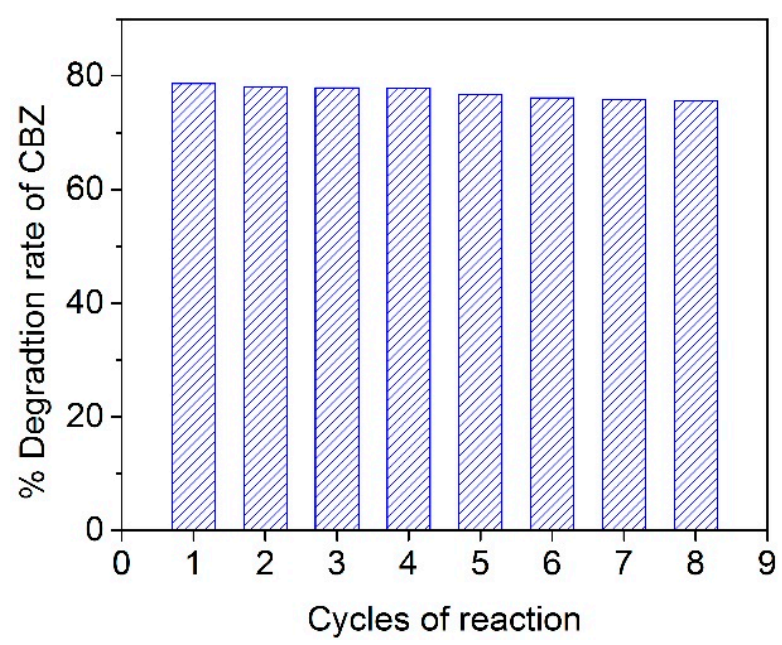

Figure 3. $\mathrm{CBZ}$ degradation in repeated experiments with the same $\mathrm{BiOBr}$ particles. $\mathrm{BiOBr}$ dose $0.5 \mathrm{~g} \cdot \mathrm{L}^{-1},[\mathrm{CBZ}]_{0}=5 \mu \mathrm{M},[\mathrm{PMS}]_{0}=1.0 \mathrm{mM}$ for all cycles, $\mathrm{pH}=7.0, \mathrm{~T}=24{ }^{\circ} \mathrm{C}$, reaction for $30 \mathrm{~min}$.

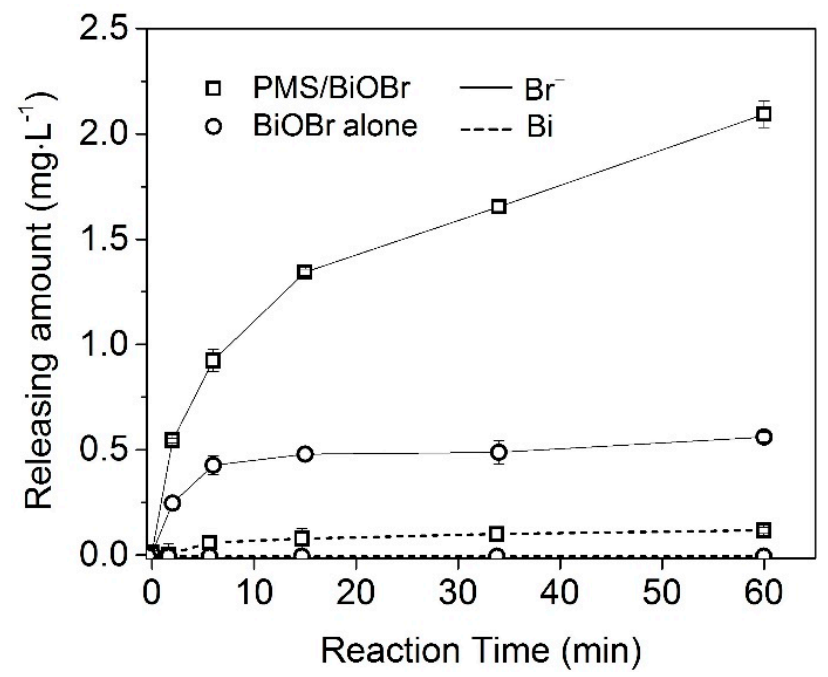

Figure 4. Leaching of $\mathrm{Bi}$ and $\mathrm{Br}^{-}$during the degradation process. $\mathrm{BiOBr}$ dose $0.5 \mathrm{~g} \cdot \mathrm{L}^{-1},[\mathrm{CBZ}]_{0}=5 \mu \mathrm{M}$, $[\mathrm{PMS}]_{0}=4.0 \mathrm{mM}, \mathrm{pH}=7.0, \mathrm{~T}=24^{\circ} \mathrm{C}$. 


\subsection{Reactive Species}

$\mathrm{H}_{2} \mathrm{O}_{2}$ and PMS have been reported to generate radicals such as $\mathrm{HO} \cdot$ and $\mathrm{SO}_{4}^{--}$in the presence of some metal oxides (ferrites [15], iron-cobalt mixed oxide [24] and $\mathrm{Co}_{3} \mathrm{O}_{4}$ [25]). Since adsorption (Figure 1a), direct oxidation by peroxides (Figure 1b), and leached bismuth ions (Text S4 and Figure S7, Supplementary Materials) make little contribution to CBZ degradation, the CBZ degradation decrease likely resulted from the attack of $\mathrm{SO}_{4}^{--}$and/or HO. generated from the activation of PMS by $\mathrm{BiOBr}$. For a direct observation, 5,5-dimethyl-1-pyrroline n-oxide (DMPO) was used to trap the radicals formed in $\mathrm{BiOCl} / \mathrm{H}_{2} \mathrm{O}_{2}$ and $\mathrm{BiOBr} / \mathrm{PMS}$ systems (Figure 5). The hyperfine coupling constants of DMPO radical adducts shown in Figure $5 \mathrm{a}(a(\mathrm{~N}) 1.48 \mathrm{mT}, a(\mathrm{H}) 1.47 \mathrm{mT})$ are consistent with the assignment of an $\mathrm{HO}$. adduct, proving the formation of $\mathrm{HO}$. in the $\mathrm{BiOCl} / \mathrm{H}_{2} \mathrm{O}_{2}$ system. The signal of an $\mathrm{SO}_{4}^{--}$adduct $(a(\mathrm{~N}) 1.36 \mathrm{mT}, a(\mathrm{H}) 1.02 \mathrm{mT}, a(\mathrm{H}) 0.15 \mathrm{mT}, a(\mathrm{H}) 0.08 \mathrm{mT},[26])$, as well as the signal of an $\mathrm{HO}$ - adduct, were detected in the $\mathrm{BiOBr} / \mathrm{PMS}$ system (Figure $5 \mathrm{~b}$ ), indicating that both $\mathrm{SO}_{4}^{-}$and $\mathrm{HO}$. were generated during the reaction. These rapidly degraded CBZ in the BiOBr/PMS system. These results confirm that radical reactions on the $\mathrm{BiOBr}$ catalyst-water interface indeed dominated the CBZ degradation in peroxide/BiOX systems.

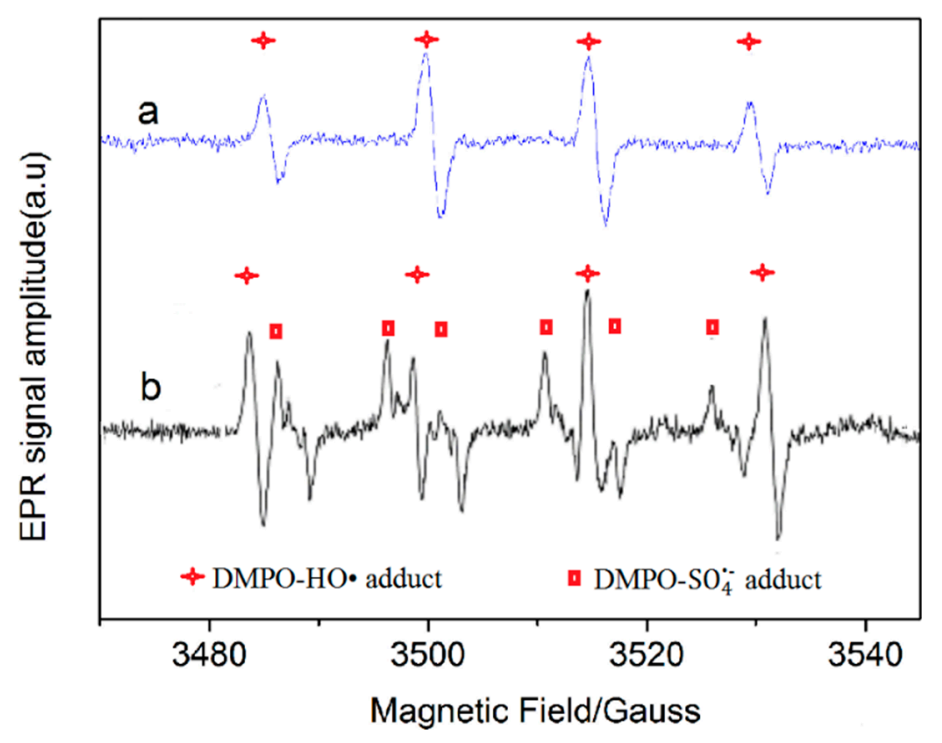

Figure 5. Electron paramagnetic resonance (EPR) spectra obtained from (a) $\mathrm{BiOBr} / \mathrm{H}_{2} \mathrm{O}_{2}$ and (b) $\mathrm{BiOBr} / \mathrm{PMS}$ systems in the presence of DMPO. BiOBr dose $0.5 \mathrm{~g} \cdot \mathrm{L}^{-1}$, [DMPO $]_{0}=100 \mathrm{mM}$, $[\mathrm{CBZ}]_{0}=5 \mu \mathrm{M},[\mathrm{PMS}]_{0}=4.0 \mathrm{mM}, \mathrm{pH}=7.0, \mathrm{~T}=24^{\circ} \mathrm{C}$.

The widely-accepted mechanism for $\mathrm{SO}_{4}^{--}$formation in PMS heterogeneous catalysis with metal oxides involves the initial substitution of PMS for $-\mathrm{OH}$ with the consequent oxidation of metal ions from a low to a higher valence [16]. The high-valence metal ions are then reduced and thus regenerated by PMS. This mechanism requires that the $\mathrm{M}^{\mathrm{x}+} / \mathrm{M}^{\mathrm{y}+}$ redox couple of the metal oxide has a higher reduction potential than that of $\mathrm{PMS}\left(\mathrm{HSO}_{5}^{-}\right)$.

$\mathrm{BiOBr}$ can form surface $-\mathrm{OH}\left(\equiv \mathrm{Bi}(\mathrm{III})-{ }^{-} \mathrm{OH}_{\mathrm{s}}\right)$ and interlayer $-\mathrm{OH}\left(\equiv \mathrm{Bi}(\mathrm{III})-{ }^{-} \mathrm{OH}_{\text {inter }}\right)$ through dissociative adsorption of water (Equation (11), [15]) and hydrolysis (Equation (12), [21]). This is evidenced by the increasing concentration of bromide in the BiOBr slurry (Figure 3). PMS can undergo direct ion exchange with $\mathrm{Br}$ atoms (-Br) (Equation (13), [14]) and complexation with Bi atoms in the $\left[\mathrm{Bi}_{2} \mathrm{O}_{2}\right]$ layer through substitution of $-\mathrm{OH}$ (Equation (14)). It has been reported that surface $\mathrm{Bi}(\mathrm{III})$ in $\mathrm{BiOCl}$ can be oxidized to a high-valence state [27]. Furthermore, the accumulation of bismuth ion in the solution as the reaction proceeds (Figure 4 ) and promotion of CBZ degradation by homogeneous Bi(III) (Text S4 and Figure S7, Supplementary Materials) suggest that Bi(III) on the surface of BiOBr particles might be the active sites. Additionally, the reduction potential of $\mathrm{Bi}(\mathrm{V})$ to $\mathrm{Bi}(\mathrm{III})$ has been reported to 
be $2.0 \mathrm{~V}$ [28], which is higher than that of PMS. Thus, the possible surface reactions generating $\mathrm{SO}_{4}^{--}$in the $\mathrm{BiOBr} / \mathrm{PMS}$ process can be specified as follows:

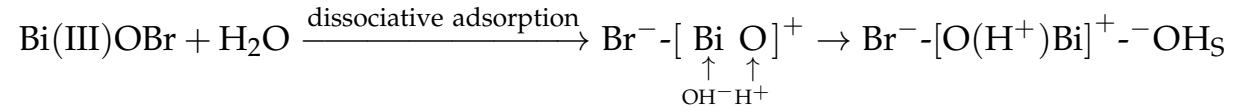

$$
\begin{aligned}
& \mathrm{Br}^{-}-\left[\mathrm{O}\left(\mathrm{H}^{+}\right) \mathrm{Bi}\right]^{+}{ }_{-}{ }^{-} \mathrm{OH}_{\mathrm{s}}+\mathrm{H}_{2} \mathrm{O} \stackrel{\text { hydrolysis }}{\longrightarrow} \mathrm{HO}_{\text {inter }}^{-}\left[\mathrm{O}\left(\mathrm{H}^{+}\right) \mathrm{Bi}\right]^{+}{ }_{-}^{-} \mathrm{OH}_{\mathrm{s}}+\mathrm{Br}^{-}+\mathrm{H}^{+} \\
& \mathrm{Br}^{-}-\left[\mathrm{O}\left(\mathrm{H}^{+}\right) \mathrm{Bi}^{+}\right]_{-}^{-} \mathrm{OH}_{\mathrm{s}}+\mathrm{HSO}_{5}^{-} \rightarrow{ }^{-} \mathrm{SO}_{3} \mathrm{O}(\mathrm{HO})-\left[\mathrm{O}\left(\mathrm{H}^{+}\right) \mathrm{Bi}\right]^{+}-\mathrm{OH}_{\mathrm{s}}+\mathrm{Br}^{-} \\
& \equiv \mathrm{Bi}(\mathrm{III}){ }^{-} \mathrm{OH}_{\mathrm{s}} /{ }^{-} \mathrm{OH}_{\text {inter }}+\mathrm{HSO}_{5}^{-} \rightarrow \equiv \mathrm{Bi}(\mathrm{III})-(\mathrm{HO}) \mathrm{OSO}_{3}^{-}+\mathrm{OH}^{-} \\
& \equiv \mathrm{Bi}(\mathrm{III})-(\mathrm{HO}) \mathrm{OSO}_{3}^{-} \rightarrow \equiv \mathrm{Bi}(\mathrm{IV}){ }^{-} \mathrm{OH}_{\mathrm{s}} /{ }^{-} \mathrm{OH}_{\text {inter }}+\mathrm{SO}_{4}^{-} \\
& \equiv \mathrm{Bi}(\mathrm{IV})-^{-} \mathrm{OH}_{\mathrm{s}} /{ }^{-} \mathrm{OH}_{\text {inter }}+\mathrm{HSO}_{5}^{-} \rightarrow \equiv \mathrm{Bi}(\mathrm{IV})-(\mathrm{HO}) \mathrm{OSO}_{3}^{-}+\mathrm{OH}^{-} \\
& \equiv \mathrm{Bi}(\mathrm{IV})-(\mathrm{HO}) \mathrm{OSO}_{3}^{-} \rightarrow \equiv \mathrm{Bi}(\mathrm{V})-^{-} \mathrm{OH}_{\mathrm{s}} /{ }^{-} \mathrm{OH}_{\text {inter }}+\mathrm{SO}_{4}^{--} \\
& \equiv \mathrm{Bi}(\mathrm{V}){ }^{-}{ }^{-} \mathrm{OH}_{\mathrm{s}} /{ }^{-} \mathrm{OH}_{\text {inter }}+\mathrm{HSO}_{5}^{-} \rightarrow \equiv \mathrm{Bi}(\mathrm{IV})-\mathrm{OOSO}_{3}^{-}+\mathrm{H}_{2} \mathrm{O} \\
& 2 \equiv \mathrm{Bi}(\mathrm{IV})-\mathrm{OOSO}_{3}^{-}+2 \mathrm{H}_{2} \mathrm{O} \rightarrow 2 \equiv \mathrm{Bi}(\mathrm{IV})-^{-} \mathrm{OH}_{\mathrm{s}} /{ }^{-} \mathrm{OH}_{\text {inter }}+2 \mathrm{SO}_{4}^{--}+\mathrm{O}_{2}+2 \mathrm{H}^{+} \\
& \equiv \mathrm{Bi}(\mathrm{IV})-^{-} \mathrm{OH}_{\mathrm{s}} /{ }^{-} \mathrm{OH}_{\text {inter }}+\mathrm{HSO}_{5}^{-} \rightarrow \equiv \mathrm{Bi}(\mathrm{III})-\mathrm{OOSO}_{3}^{-}+\mathrm{H}_{2} \mathrm{O} \\
& 2 \equiv \mathrm{Bi}(\mathrm{III})-\mathrm{OOSO}_{3}^{-}+2 \mathrm{H}_{2} \mathrm{O} \rightarrow 2 \equiv \mathrm{Bi}(\mathrm{III}){ }^{-} \mathrm{OH}_{\mathrm{s}} /{ }^{-} \mathrm{OH}_{\text {inter }}+2 \mathrm{SO}_{4}^{--}+\mathrm{O}_{2}+2 \mathrm{H}^{+} \text {. }
\end{aligned}
$$

The complexation of BiOBr and PMS was directly confirmed by the ATR-FTIR data (Figure 6). The infrared bands at around $1249 \mathrm{~cm}^{-1}$ have been reported as arising from S-O bond stretching vibrations of PMS [29]. This band (peaking at $1257 \mathrm{~cm}^{-1}$ in Figure $6 \mathrm{a}$ and at $1250 \mathrm{~cm}^{-1}$ in Figure $6 \mathrm{~b}$ ) obviously weakened when $\mathrm{BiOBr}$ was introduced into the PMS solution. Meanwhile, BiOBr caused the S-O vibration band of the PMS to shift by $7 \mathrm{~cm}^{-1}$; conversely, PMS decreased the band of the surface $-\mathrm{OH}$ of $\mathrm{BiOBr}$ (peak at $3165 \mathrm{~cm}^{-1}$ ) (Figure 6c). These two points support Equation (14).

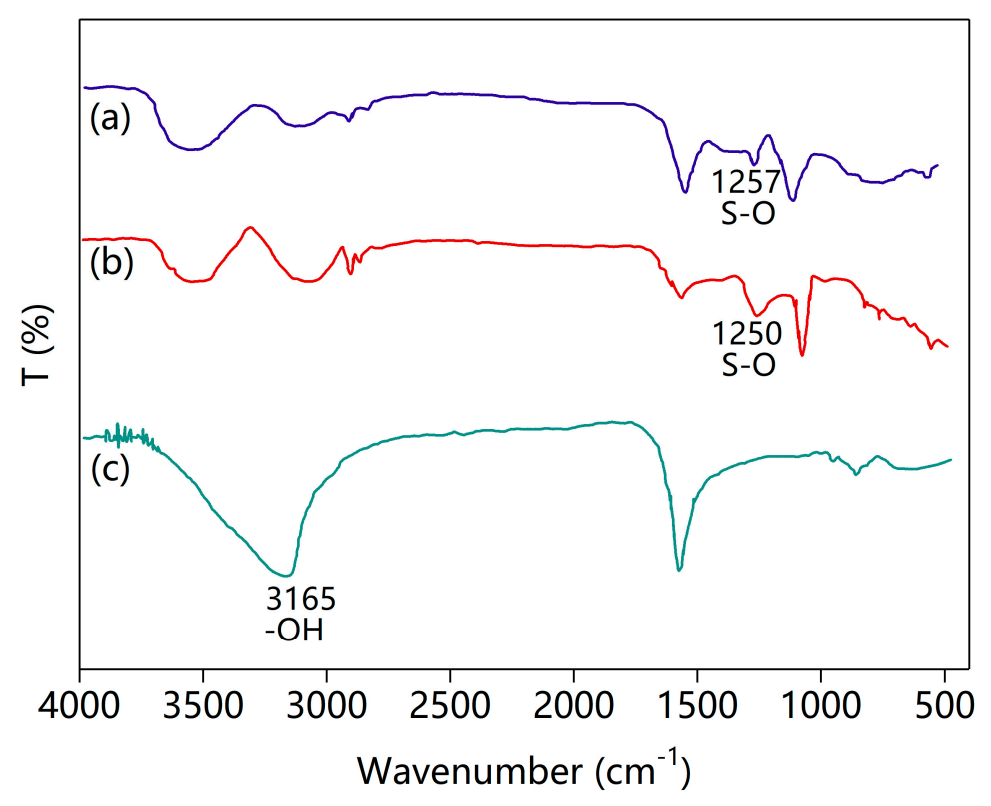

Figure 6. Attenuated total reflectance Fourier transform infrared (ATR-FTIR) spectra of (a) mixture of PMS and $\mathrm{BiOBr},(\mathbf{b}) \mathrm{PMS}$ solution and (c) BiOBr suspension. Initial $\mathrm{pH}$ of the pure water was 5.7; the PMS solution was adjusted to $\mathrm{pH}$ 5.7. 
The changes in the metal's valence during the reaction were identified by X-ray photoelectron spectroscopy (XPS). As Figure 7a shows, there were two strong peaks (at 159.60 and $164.95 \mathrm{eV}$ ) in the Bi region, indicating that $\mathrm{Bi}(\mathrm{III})$ was present [30]. Peaks with higher binding energies at 159.69 and $159.77 \mathrm{eV}$ (Figure $7 \mathrm{~b}, \mathrm{c}$, respectively) can be attributed to $\mathrm{Bi}(\mathrm{III}+\mathrm{x})$ ions (Bi(IV) or $\mathrm{Bi}(\mathrm{V})$ ) [27]. The XPS data thus help to elucidate the possible electron-transfer reactions on the surface of the BiOBr particles (Equations (15)-(21)).

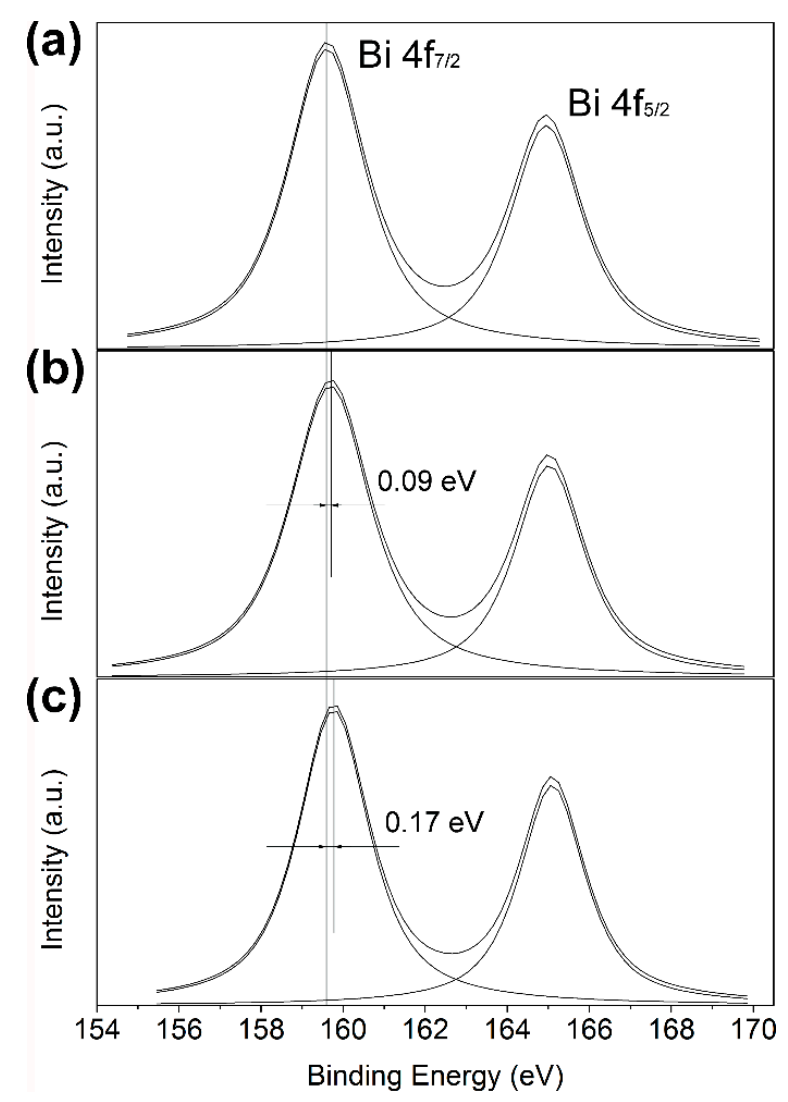

Figure 7. XPS spectra of the Bi4f region for (a) BiOBr virgin, (b) BiOBr collected after 30-min reaction time and (c) BiOBr collected after 60-min reaction time. BiOBr dose $0.5 \mathrm{~g} \cdot \mathrm{L}^{-1},[\mathrm{CBZ}]_{0}=5 \mu \mathrm{M}$, $[\mathrm{PMS}]_{0}=4.0 \mathrm{mM}, \mathrm{pH}=7.0, \mathrm{~T}=24^{\circ} \mathrm{C}$.

Two more issues must be addressed to quantitatively explain the excellent performance observed: (1) the reaction rate constants of $\mathrm{CBZ}$ with $\mathrm{HO} \cdot$ and $\mathrm{SO}_{4}^{--}$and (2) the respective contribution of the two radicals.

The CBZ degradation was mainly induced by $\mathrm{HO}$ and $\mathrm{SO}_{4}^{--}$attack. These are both strong one-electron oxidants. The kinetics of CBZ degradation are therefore likely to be second-order, as in Equation (22). Equation (23) is the result of the integration of Equation (22) as follows:

$$
\begin{aligned}
& -\frac{d[\mathrm{CBZ}]}{d t}=\left(k_{1} \int\left[\mathrm{SO}_{4}^{--}\right] d t+\int[\mathrm{HO} \cdot] d t\right)[\mathrm{CBZ}], \\
& -\ln \frac{[\mathrm{CBZ}]}{[\mathrm{CBZ}]_{0}}=\left(k_{1} \int\left[\mathrm{SO}_{4}^{--}\right] d t+k_{2} \int[\mathrm{HO} \cdot] d t\right) d t,
\end{aligned}
$$

where $\mathrm{k}_{1}$ and $k_{2}$ are the reaction rate constants of $\mathrm{CBZ}$ with $\mathrm{HO} \cdot$ and $\mathrm{SO}_{4}^{--}$, respectively, and $[\mathrm{CBZ}]_{0}$ and [CBZ] are the CBZ concentrations at the start of the reaction and at time $t$, respectively. Assuming pseudo-steady state, Equation (23) can be simplified to Equation (24): 


$$
-\ln \frac{[\mathrm{CBZ}]}{[\mathrm{CBZ}]_{0}}=\left(k_{1}\left[\mathrm{SO}_{4}^{--}\right]_{\mathrm{sS}}+k_{2}[\mathrm{HO} \cdot]_{s s}\right) t=\left(k_{1}^{*}+k_{2}^{*}\right) t,
$$

where $\left[\mathrm{SO}_{4}^{--}\right]_{\mathrm{Ss}}$ and [HO- $]_{\mathrm{ss}}$ are the quasi-stationary concentrations of $\mathrm{SO}_{4}^{--}$and $\mathrm{HO} \cdot$, respectively, and $k_{1}^{*}$ and $k_{2}^{*}$ are $k_{1}\left[\mathrm{SO}_{4}^{--}\right]_{\mathrm{sS}}$ and $k_{2}[\mathrm{HO} \cdot]_{s S^{\prime}}$, respectively. Thus, the contribution of $\mathrm{SO}_{4}^{--}$can be expressed as $k_{1}^{*} /\left(k_{1}^{*}+k_{2}^{*}\right)$.

$\mathrm{HO} \cdot$ has been reported to attack CBZ with a kinetic constant of $2.05 \times 10^{9} \mathrm{M}^{-1} \cdot \mathrm{s}^{-1}$ [31], and a second-order rate constant of $1.62 \times 10^{9} \mathrm{M}^{-1} \cdot \mathrm{s}^{-1}$ can be determined for $\mathrm{SO}_{4}^{--}$(Text S5 and Figure S8 in the Supplementary Materials). Both radicals showed nearly diffusion-controlled reactivity with CBZ, which suggests reasonably efficient degradation. The degradation at low initial CBZ concentration $(\leq 5 \mu \mathrm{M})$ was well fitted with a pseudo first-order kinetic model, with high values of the correlation coefficient during the initial $7 \mathrm{~min}$ of the reaction time (Figure 8). This finding suggests that $k_{1}^{*}+k_{2}^{*}$ can be assumed to be constant. To determine the contribution of each radical, tertiary butanol (TBA) was added and $k_{1}^{*}+k_{2}^{*}$ was estimated by fitting a pseudo first-order constant (Figure S9, Supplementary Materials). HO was considered to be scavenged by the TBA; thus $k_{2}^{*}$ can be ignored. $k_{1}^{*} /\left(k_{1}^{*}+k_{2}^{*}\right)$ was calculated to be $67.3 \%\left(k_{2}^{*}=0.302, k_{1}^{*}+k_{2}^{*}=0.449\right)$ at neutral $\mathrm{pH}$. This result tends to confirm that the $67.3 \% \mathrm{CBZ}$ degradation was due primarily to $\mathrm{SO}_{4}^{-{ }^{-}}$-mediated oxidation.

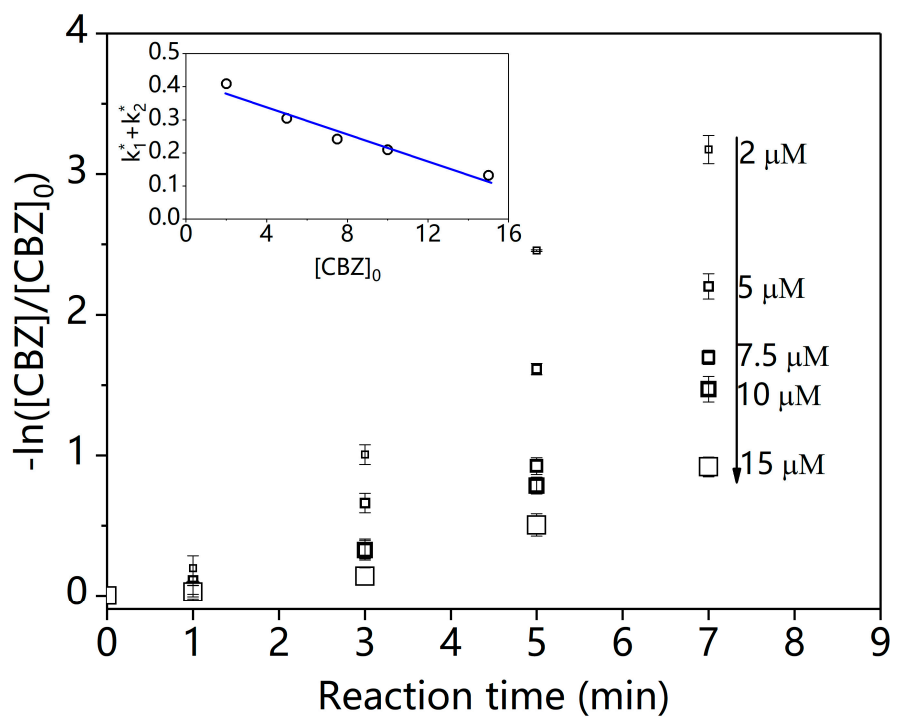

Figure 8. The degradation performance of $\mathrm{CBZ}$ by $\mathrm{BiOBr} / \mathrm{PMS}$ process at different initial concentration of CBZ. BiOBr dose $0.5 \mathrm{~g} \cdot \mathrm{L}^{-1},[\mathrm{PMS}]_{0}=4.0 \mathrm{mM}, \mathrm{pH}=7.0, \mathrm{~T}=24{ }^{\circ} \mathrm{C}$.

\subsection{Bromate Formation}

Bromate formation in bromide-containing solution in the presence of $\mathrm{SO}_{4}^{--}$or $\mathrm{HO}$. has been reported [32]. As for the $\mathrm{BiOBr} / \mathrm{PMS}$ system, bromide-ion releasing (Figure 4) and radicals $\left(\mathrm{SO}_{4}^{--}\right.$and HO., Figure 5) have been detected, and bromate formation should be given concern. Therefore, bromate formation during treatment of three actual waters (ESF, TP and QZL) was compared with that of ultrapure water (Figure 9). Within a 30-min reaction time, no detectable bromate formation $\left(<0.002 \mu \mathrm{g} \cdot \mathrm{L}^{-1}\right)$ for ESF and QZL has been observed, while significant bromate formation happened for ultrapure water $(14.3 \mu \mathrm{M})$ and TP $(1.2 \mu \mathrm{M})$. Suppression of bromate formation by natural organic matters in AOTs has been reported [32,33], which is ascribed to scavenging of reactive bromine species and radicals by natural organic matter. A similar effect caused by DOM in ESF, TP and QZL is expected. It is important to highlight that the scavenging of reactive bromine species by natural organic matter or CBZ would pose a risk of yielding organobromated byproducts. 


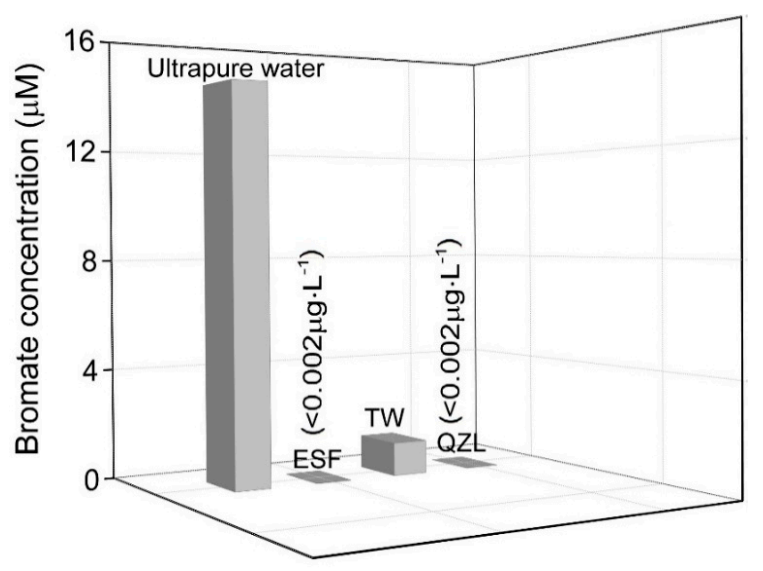

Figure 9. Formation of bromate in three real waters treated by $\mathrm{PMS} / \mathrm{BiOBr}$. BiOBr dose $1.0 \mathrm{~g} \cdot \mathrm{L}^{-1}$, $[\mathrm{CBZ}]_{0}=5 \mu \mathrm{M},[\mathrm{PMS}]_{0}=4.0 \mathrm{mM}, \mathrm{pH}=7.0, \mathrm{~T}=24{ }^{\circ} \mathrm{C}$.

\subsection{Detoxification Performance}

The system's acute toxicity was tested using BiOBr as the PMS activator (Figure 10). The toxicity toward Vibrio fisheri decreased as the CBZ was eliminated, but over the entire course of the degradation the toxicity decreased more slowly than the CBZ concentration. That suggests that some degradation byproducts also displayed toxicity. Similar to the toxicity, the total organic carbon (TOC) also decreased more slowly than the CBZ concentration. For a $78.2 \%$ degradation of CBZ, only $39.7 \%$ of the TOC was removed. These results indicate that a long reaction time may be needed to treat $C B Z$ to a safe level. The toxicity evolution can be explained to some extent by exploring CBZ's degradation pathway.

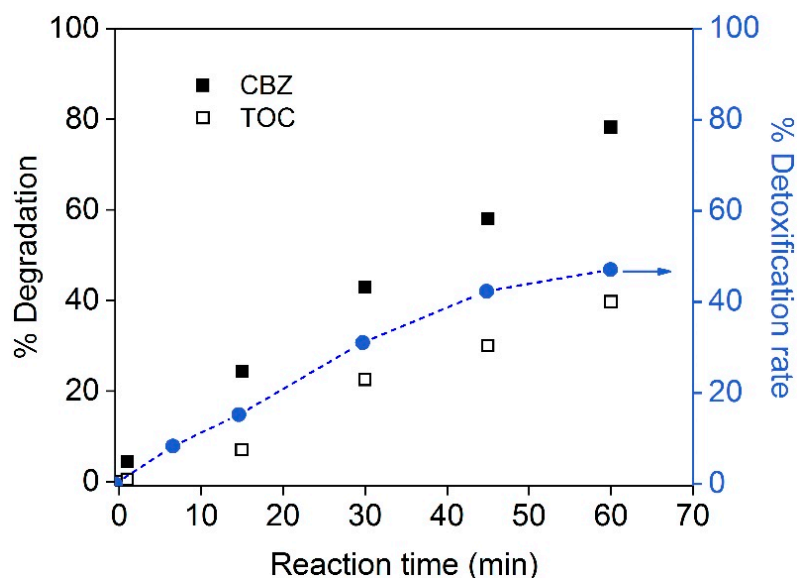

Figure 10. The toxicity evolution of $\mathrm{CBZ}$ solution degraded by $\mathrm{PMS} / \mathrm{BiOBr}$ process. $\mathrm{BiOBr}$ dose $0.5 \mathrm{~g} \cdot \mathrm{L}^{-1},[\mathrm{CBZ}]_{0}=40 \mu \mathrm{M},[\mathrm{PMS}]_{0}=4.0 \mathrm{mM}, \mathrm{pH}=7.0, \mathrm{~T}=24^{\circ} \mathrm{C}$.

\subsection{Degradation Mechanism}

To elucidate the mechanism of $\mathrm{CBZ}$ degradation, the formation of intermediate products in the degradation of $0.1 \mathrm{mM} \mathrm{CBZ}$ in the presence of $4 \mathrm{mM}$ PMS and $0.5 \mathrm{~g} \cdot \mathrm{L}^{-1} \mathrm{BiOBr}$ was detected using high-performance liquid chromatography with tandem mass spectrometric detection (HPLC-MS) (Figure 11). In the figure, the CBZ signal corresponds to the positive ion at $\mathrm{m} / \mathrm{z} 237$ generated after $\mathrm{H}^{+}$addition during the electrospray ionization process. The mass-to-charge peak observed at $\mathrm{m} / \mathrm{z}$ 259 was contributed by sodium. Meanwhile, intermediates were noted at $\mathrm{m} / \mathrm{z} 180,196,210,224,239$, 251, 253 and 267. Possible molecular structures for these intermediates can be proposed on the basis 
of the specific $m / z$ values, $C B Z$ 's chemical structure and the reaction characteristics of $\mathrm{SO}_{4}^{--}$and $\mathrm{HO}$. The inferred intermediates suggest the probable degradation pathway for CBZ shown in Figure 12.
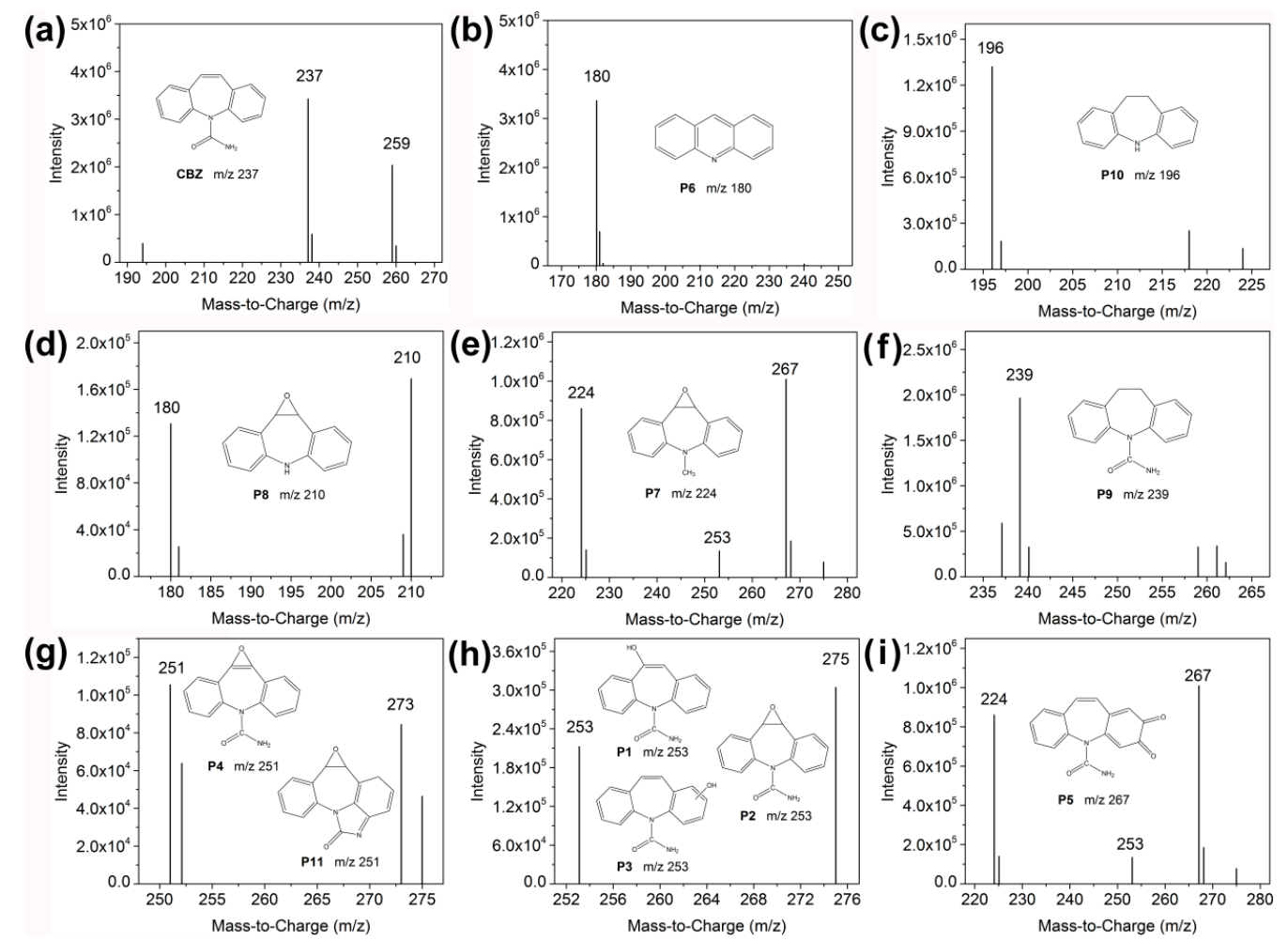

Figure 11. LC-MS spectra of (a) CBZ and the possible intermediates; (b) $m / z$ 180; (c) $m / z$ 196; (d) $m / z 210$; (e) $m / z 224$; (f) $m / z 239$; (g) $m / z 251$; (h) $m / z 253$; (i) $m / z 267$.

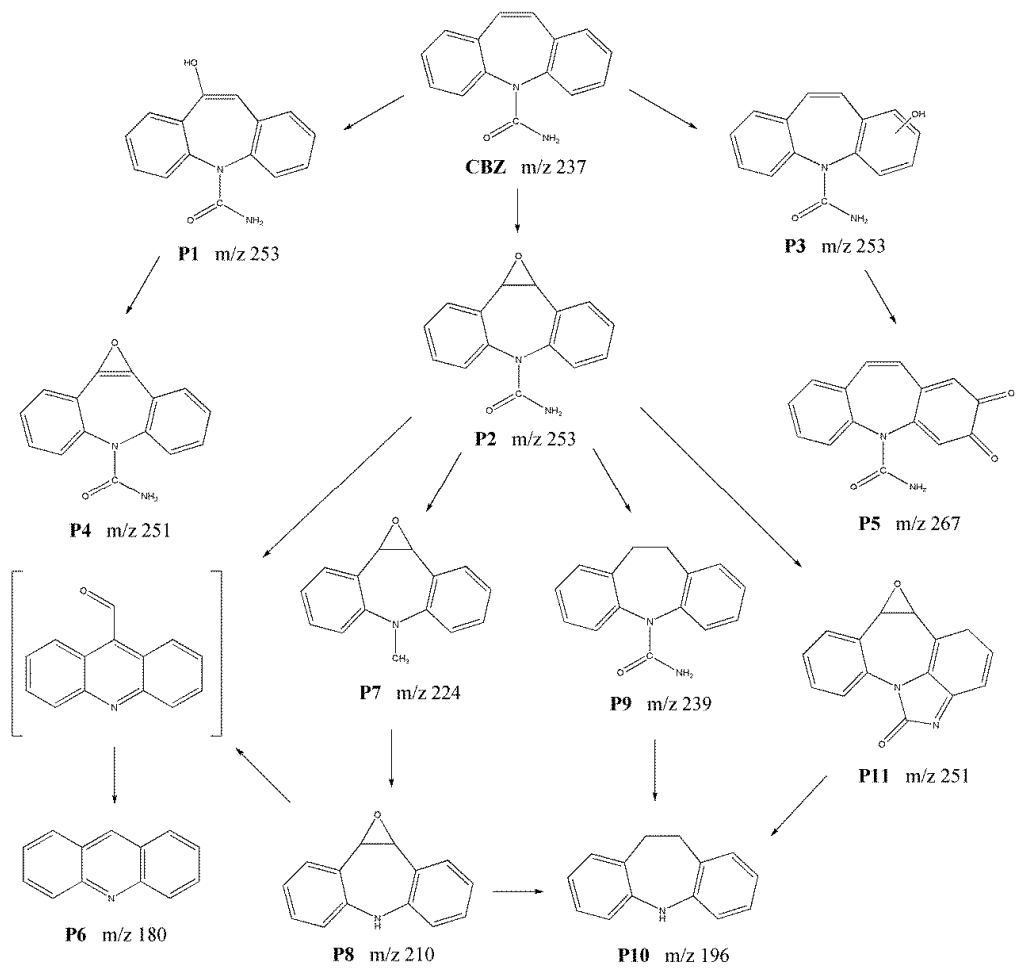

Figure 12. Tentative degradation pathway of CBZ. 
The mass peak at 253 was assigned to hydroxy-CBZ (P1 and P3) or 10,11-epoxide-CBZ (P2) on the basis of a report from Sun's group [34]. The further attack of HO- radicals on the hydroxy-CBZ (P1 and P3) induced the formation of 10,11-epoxy-CBZ (P4) and carbamazepine-o-quinone (P5) $[35,36]$. Subsequently, ring contraction in the 10,11-epoxy-CBZ caused the loss of a $-\mathrm{CONH}_{2}$ group. The deamidation produced 9-acridine-9-carboxaldehyde as an intermediate and acridine (P6) as the final form, consistent with previous reports $[37,38]$. C-N cleavage on the side chains results in the formation of P7 from P2, followed by the formation of P8. Similarly, the ring contraction could also form P11, which could further be degraded to P10. Based on these intermediates, many transformation products retain the functional structure of $\mathrm{CBZ}$ and may retain some of its biological toxicity. This effect could partly explain the observed lag in detoxification relative to the degradation of the CBZ parent molecule.

\section{Materials and Methods}

\subsection{Materials and Reagents}

Sources of chemicals and reagents are provided in the Supplementary Materials Text S1 . All chemicals were used as received.

\subsection{Synthesis and Characterization of BiOX Microstructures}

The synthesis of $\mathrm{BiOX}(\mathrm{X}=\mathrm{Cl}, \mathrm{Br}, \mathrm{I})$ microstructures was carried out through a solvothermal procedure [14]. This process yielded BiOX microspheres as shown in the scanning electron micrograph which is provided in Figure S1 in the Supplementary Materials. X-ray diffraction (XRD) analysis of a typical BiOBr specimen was conducted using a Rigaku Dmax-2000 diffractometer (Rigaku Co., Tokyo, Japan). A Bruker Optics Matrix-MF spectrometer (Bruker Optics, Ettlingen, Germany) was used for attenuated total-reflection Fourier transform infrared spectroscopy (ATR-FTIR). X-ray photoelectron spectroscopy (XPS) analysis was carried out with an ESCALAB 250Xi spectrometer (Thermo Scientific, Waltham, MA, USA). The specific surface area and average pore size were measured using an ASAP2020HD88 analyzer (Micromeritics, Norcross, GA, USA). The particle-size distribution was quantified using a Mastersizer 2000 laser particle size analyzer (Malvern Instruments Ltd., Malvern, $\mathrm{UK})$. Acid-base titration was employed to determine the point of zero charge $\left(\mathrm{pH}_{\mathrm{pzc}}\right)$.

\subsection{Experimental Procedures}

The CBZ degradation experiments were performed in a room thermostated $24{ }^{\circ} \mathrm{C}$ and under dark conditions. The $0.02 \mathrm{mM} \mathrm{CBZ}$ stock solution was stirred for $30 \mathrm{~min}$ before use. Except for the best peroxide-activator screening experiments where $1 \mathrm{mM}$ peroxide (PS, $\mathrm{PMS}$ or $\mathrm{H}_{2} \mathrm{O}_{2}$ ) was used, the $\mathrm{CBZ}$ concentration was set at $5 \mu \mathrm{M}$ and the initial concentration of peroxide (PS, $\mathrm{PMS}$ or $\mathrm{H}_{2} \mathrm{O}_{2}$ ) was kept at $4 \mathrm{mM}$ in the reaction solution. Subsequently, $0.10 \mathrm{~g}$ of the BiOX microspheres was dispersed into $200 \mathrm{~mL}$ of the reaction solution, and the $\mathrm{pH}$ was adjusted with $10 \mathrm{mM}$ Michaelis buffer (to $\mathrm{pH} 4.0$ or 5.0) or borate buffer (to $\mathrm{pH} 7.0,9.0$ or 11.0) as necessary. The anions (tartrate ion and tetraborate ion) in the buffer showed weak ion exchange (Figure S2, Supplementary Materials), which means they had little influence on the BiOX-catalyzed peroxide oxidation. During the reaction, samples were collected using a syringe at predetermined time intervals and transferred to vials containing a quencher $(100 \mu \mathrm{L}$ of $0.2 \mathrm{M} \mathrm{NaNO}_{2}$ [16]). The mixture was then filtered immediately for analysis of the CBZ concentration and to evaluate any toxicity.

\subsection{Analysis}

The CBZ content in the samples was determined using an Agilent 1200 HPLC (Agilent, Palo Alto, CA, USA) equipped with a UV-vis detector. The degradation intermediates were concentrated on a Gilson GX-271 ASPEC apparatus (Gilson, Middleton, WI, USA) and analyzed with an Agilent 6460 triple-quad HPLC-MS (Agilent, Palo Alto, CA, USA). The release of bromide $\left(\mathrm{Br}^{-}\right)$from the $\mathrm{BiOBr}$ materials and possible bromate formation were monitored using a Dionex ICS-2000 ion chromatograph 
(Dionex, Sunnyvale, CA, USA). The bismuth leaching during the degradation process was detected using a PE NexION 300Q inductively-coupled plasma mass spectrometer (Perkin Elmer, Oak Brook, IL, USA). The detailed parameters are shown in Text S2 of the Supplementary Materials.

\section{Conclusions}

This study evaluated catalytic peroxide (PMS, $\mathrm{PS}$ and $\mathrm{H}_{2} \mathrm{O}_{2}$ ) oxidation of $\mathrm{CBZ}$ using $\mathrm{BiOX}$ as the catalyst. The results show that the BiOX microsphere catalyst activated PMS most efficiently. $\mathrm{BiOBr}$ generated the best kinetics and it was found to be both efficient and stable for CBZ degradation. Sulfate radical was determined to be the primary oxidative species in the $\mathrm{BiOBr} / \mathrm{PMS}$ system. The high reduction potential of $\mathrm{Bi}(\mathrm{V}) / \mathrm{Bi}(\mathrm{III})$ facilitates the efficient formation of the sulfate radical. The degradation intermediates of CBZ retain some biotoxicity and a relatively long reaction time may be necessary to detoxify $\mathrm{CBZ}$ completely. Bromide is released from $\mathrm{BiOBr}$ in the process through hydrolysis and ion exchange, so bromate produced by the radical oxidation of bromide must be examined. Presence of dissolved organic matter acts as an inhibitor of bromate formation. Deposit of $\mathrm{BiOBr}$ onto materials with strong ion-exchange ability to locate bromide ions may relieve such concern. In addition, bismuth leaching, although very slow, is expected to shorten the catalyst's lifespan. Modifications, such as metal doping, may be necessary to improve the stability and recyclability of BiOBr.

Supplementary Materials: The following are available online at www.mdpi.com/2073-4344/7/11/315/s1, Text S1: Chemicals, Text S2: Parameters of analysis, Text S3: Toxicity evaluation of samples, Text S4: Effect of leaching bismuth ion, Text S5: Determination of $k\left(\mathrm{SO}_{4}^{--}+\mathrm{CBZ}\right)$, Figure S1: SEM images of BiOX microspheres: (a) $\mathrm{BiOCl}$, (b) $\mathrm{BiOBr}$, (c) BiOI, Figure S2: Effect of anions in buffer on the releasing of bromide ion, Figure S3: Comparison of CBZ degradation by PMS/BiOBr and PMS/CuFe $\mathrm{O}_{4}$, Figure S4: Normalized degradation rate of CBZ based on specific surface area for PMS/BiOBr, Figure S5: Color change of BiOI suspension during the degradation process, Figure S6: XRD spectra of BiOBr particles before and after the repeated catalytic PMS oxidation (7 cycles), Figure S7. Effect of leaching bismuth ion on the degradation of CBZ, Figure S8: $-\ln \left([\mathrm{CBZ}] /[\mathrm{CBZ}]_{0}\right)$ vs. $-\ln \left([p \mathrm{CBA}] /[p \mathrm{CBA}]_{0}\right)$, Figure S9: CBZ degradation in the presence or absence of TBA, Table S1: BET surface area, average pore and particle size, and $\mathrm{pHpzc}$ of $\mathrm{BiOX}(\mathrm{X}=\mathrm{Cl}, \mathrm{Br}, \mathrm{I})$.

Acknowledgments: This work was financially supported by the National Natural Science Foundation of China (Grant No. 51408539 and 51478417), the Public Projects of Zhejiang Province (Grant No. 2017C33174), the Major International (Regional) Joint Research Program of China (No.51761145022), and the National Key Research and Development Program of China (No. 2016YFC0400601, 2016YFC0400606). The authors also greatly appreciate the additional support from Jiyang College of Zhejiang A \& F University (Grant No. 04251700010) and the special S\&T project on the treatment and control of water pollution (Grant No. 2017ZX07201-003).

Author Contributions: X.L. and M.Y. conceived and designed the experiments; T.Z., S.C., J.L., and L.W. performed the experiments and analyzed the data; R.C. and Y.S. contributed reagents/materials/analysis tools; L.W. wrote the paper.

Conflicts of Interest: The authors declare no conflict of interest.

\section{References}

1. Miao, X.; Metcalfe, C.D. Determination of carbamazepine and its metabolites in aqueous samples using liquid chromatography-electrospray tandem mass spectrometry. Anal. Chem. 2003, 75, 3731-3738. [CrossRef] [PubMed]

2. Ternes, T.A. Occurrence of drugs in german sewage treatment plants and rivers. Water Res. 1998, 32, 3245-3260. [CrossRef]

3. Heberer, T. Tracking persistent pharmaceutical residues from municipal sewage to drinking water. J. Hydrol. 2002, 266, 175-189. [CrossRef]

4. Ginebreda, A.; Muñoz, I.; de Alda, M.L.; Brix, R.; López-Doval, J.; Barceló, D. Environmental risk assessment of pharmaceuticals in rivers: Relationships between hazard indexes and aquatic macroinvertebrate diversity indexes in the Llobregat River (NE Spain). Environ. Int. 2010, 36, 153-162. [CrossRef] [PubMed]

5. Benotti, M.J.; Trenholm, R.A.; Vanderford, B.J.; Holady, J.C.; Stanford, B.D.; Snyder, S.A. Pharmaceuticals and endocrine disrupting compounds in us drinking water. Environ. Sci. Technol. 2008, 43, 597-603. [CrossRef] 
6. Zhang, Y.; Geißen, S.U.; Gal, C. Carbamazepine and diclofenac: Removal in wastewater treatment plants and occurrence in water bodies. Chemosphere 2008, 73, 1151-1161. [CrossRef] [PubMed]

7. Clara, M.; Strenn, B.; Kreuzinger, N. Carbamazepine as a possible anthropogenic marker in the aquatic environment: Investigations on the behaviour of carbamazepine in wastewater treatment and during groundwater infiltration. Water Res. 2004, 38, 947-954. [CrossRef] [PubMed]

8. Joss, A.; Keller, E.; Alder, A.C.; Göbel, A.; McArdell, C.S.; Ternes, T.; Siegrist, H. Removal of pharmaceuticals and fragrances in biological wastewater treatment. Water Res. 2005, 39, 3139-3152. [CrossRef] [PubMed]

9. Radjenovic, J.; Petrovic, M.; Barceló, D. Analysis of pharmaceuticals in wastewater and removal using a membrane bioreactor. Anal. Bioanal. Chem. 2007, 387, 1365-1377. [CrossRef] [PubMed]

10. Carballa, M.; Omil, F.; Lema, J.M.; Llompart, M.; Garcia-Jares, C.; Rodriguez, I.; Gómez, M.; Ternes, T. Behavior of pharmaceuticals, cosmetics and hormones in a sewage treatment plant. Water Res. 2004, 38, 2918-2926. [CrossRef] [PubMed]

11. Suárez, S.; Carballa, M.; Omil, F.; Lema, J.M. How are pharmaceutical and personal care products (PPCPs) removed from urban wastewaters? Rev. Environ. Sci. Biotechnol. 2008, 7, 125-138. [CrossRef]

12. Wang, X.; Yang, W.; Li, F.; Zhao, J.; Liu, R.; Liu, S.; Li, B. Construction of amorphous $\mathrm{TiO}_{2} / \mathrm{BiOBr}$ heterojunctions via facets coupling for enhanced photocatalytic activity. J. Hazard. Mater. 2015, 292, 126-136. [CrossRef] [PubMed]

13. Cheng, H.; Huang, B.; Dai, Y. Engineering BiOX $(\mathrm{X}=\mathrm{Cl}, \mathrm{Br}, \mathrm{I})$ nanostructures for highly efficient photocatalytic applications. Nanoscale 2014, 6, 2009-2026. [CrossRef] [PubMed]

14. Li, J.; Sun, S.; Qian, C.; He, L.; Chen, K.; Zhang, T.; Chen, Z.; Ye, M. The role of adsorption in photocatalytic degradation of ibuprofen under visible light irradiation by BiOBr microspheres. Chem. Eng. J. 2016, 297, 139-147. [CrossRef]

15. Guan, Y.; Ma, J.; Ren, Y.; Liu, Y.; Xiao, J.; Lin, L.; Zhang, C. Efficient degradation of atrazine by magnetic porous copper ferrite catalyzed peroxymonosulfate oxidation via the formation of hydroxyl and sulfate radicals. Water Res. 2013, 47, 5431-5438. [CrossRef] [PubMed]

16. Zhang, T.; Zhu, H.; Croué, J.P. Production of sulfate radical from peroxymonosulfate induced by a magnetically separable $\mathrm{CuFe}_{2} \mathrm{O}_{4}$ spinel in water: Efficiency, stability, and mechanism. Environ. Sci. Technol. 2013, 47, 2784-2791. [CrossRef] [PubMed]

17. Wang, Y.; Hong, C. Effect of hydrogen peroxide, periodate and persulfate on photocatalysis of 2-chlorobiphenyl in aqueous $\mathrm{TiO}_{2}$ suspensions. Water Res. 1999, 33, 2031-2036. [CrossRef]

18. Rastogi, A.; Al-Abed, S.R.; Dionysiou, D.D. Effect of inorganic, synthetic and naturally occurring chelating agents on Fe(II) mediated advanced oxidation of chlorophenols. Water Res. 2009, 43, 684-694. [CrossRef] [PubMed]

19. Yang, S.; Wang, P.; Yang, X.; Shan, L.; Zhang, W.; Shao, X.; Niu, R. Degradation efficiencies of azo dye acid orange 7 by the interaction of heat, $\mathrm{uv}$ and anions with common oxidants: Persulfate, peroxymonosulfate and hydrogen peroxide. J. Hazard. Mater. 2010, 179, 552-558. [CrossRef] [PubMed]

20. Von Sonntag, C. Advanced oxidation processes: Mechanistic aspects. Water Sci. Technol. 2008, 58, $1015-1021$. [CrossRef] [PubMed]

21. Taylor, P.; Lopata, V.J. Some phase relationships between basic bismuth chlorides in aqueous solutions at $25^{\circ}$ C. Can. J. Chem. 1987, 65, 2824-2829. [CrossRef]

22. Yang, Y.; Pignatello, J.J.; Ma, J.; Mitch, W.A. Comparison of halide impacts on the efficiency of contaminant degradation by sulfate and hydroxyl radical-based advanced oxidation processes (AOPs). Environ. Sci. Technol. 2014, 48, 2344-2351. [CrossRef] [PubMed]

23. House, D.A. Kinetics and mechanism of oxidations by peroxydisulfate. Chem. Rev. 1962, 62, $185-203$. [CrossRef]

24. Yang, Q.; Choi, H.; Al-Abed, S.R.; Dionysiou, D.D. Iron-cobalt mixed oxide nanocatalysts: Heterogeneous peroxymonosulfate activation, cobalt leaching, and ferromagnetic properties for environmental applications. Appl. Catal. B Environ. 2009, 88, 462-469. [CrossRef]

25. Anipsitakis, G.P.; Stathatos, E.; Dionysiou, D.D. Heterogeneous activation of oxone using $\mathrm{Co}_{3} \mathrm{O}_{4}$. J. Phys. Chem. B 2005, 109, 13052-13055. [CrossRef] [PubMed]

26. Furman, O.S.; Teel, A.L.; Watts, R.J. Mechanism of base activation of persulfate. Environ. Sci. Technol. 2010, 44, 6423-6428. [CrossRef] [PubMed] 
27. Zhang, L.; Wang, W.; Jiang, D.; Gao, E.; Sun, S. Photoreduction of $\mathrm{CO}_{2}$ on BiOCl nanoplates with the assistance of photoinduced oxygen vacancies. Nano Res. 2015, 8, 821-831. [CrossRef]

28. Bard, A.J.; Parsons, R.; Jordan, J. Standard Potentials in Aqueous Solution; Marcel Dekker, Inc.: New York, NY, USA, 1985; pp. 180-187.

29. Gonzalez, J.; Torrent-Sucarrat, M.; Anglada, J.M. The reactions of $\mathrm{SO}_{3}$ with $\mathrm{HO}_{2}$ radical and $\mathrm{H}_{2} \mathrm{O} \ldots$ $\mathrm{HO}_{2}$ radical complex. Theoretical study on the atmospheric formation of $\mathrm{HSO}_{5}$ and $\mathrm{H}_{2} \mathrm{SO}_{4}$. Phys. Chem. Chem. Phys. 2010, 12, 2116-2125. [CrossRef] [PubMed]

30. Ye, L.; Jin, X.; Liu, C.; Ding, C.; Xie, H.; Chu, K.; Wong, P. Thickness-ultrathin and bismuth-rich strategies for BiOBr to enhance photoreduction of $\mathrm{CO}_{2}$ into solar fuels. Appl. Catal. B Environ. 2016, 187, 281-290. [CrossRef]

31. Vogna, D.; Marotta, R.; Andreozzi, R.; Napolitano, A.; d'Ischia, M. Kinetic and chemical assessment of the $\mathrm{UV} / \mathrm{H}_{2} \mathrm{O}_{2}$ treatment of antiepileptic drug carbamazepine. Chemosphere 2004, 54, 497-505. [CrossRef]

32. Lutze, H.V.; Bakkour, R.; Kerlin, N.; von Sonntag, C.; Schmidt, T.C. Formation of bromate in sulfate radical based oxidation: Mechanistic aspects and suppression by dissolved organic matter. Water Res. 2014, 53, 370-377. [CrossRef] [PubMed]

33. Fang, J.; Shang, C. Bromate formation from bromide oxidation by the UV/persulfate process. Environ. Sci. Technol. 2012, 46, 8976-8983. [CrossRef] [PubMed]

34. Guan, Y.; Ma, J.; Li, X.; Fang, J.; Chen, L. Influence of $\mathrm{pH}$ on the formation of sulfate and hydroxyl radicals in the UV/peroxymonosulfate system. Environ. Sci. Technol. 2011, 45, 9308-9314. [CrossRef] [PubMed]

35. Monsalvo, V.M.; Lopez, J.; Munoz, M.; de Pedro, Z.M.; Casas, J.A.; Mohedano, A.F.; Rodriguez, J.J. Application of Fenton-like oxidation as pre-treatment for carbamazepine biodegradation. Chem. Eng. J. 2015, 264, 856-862. [CrossRef]

36. Rao, Y.F.; Qu, L.; Yang, H.; Chu, W. Degradation of carbamazepine by Fe(II)-activated persulfate process. J. Hazard. Mater. 2014, 268, 23-32. [CrossRef] [PubMed]

37. Daghrir, R.; Drogui, P.; Dimboukou-Mpira, A.; El Khakani, M. Photoelectrocatalytic degradation of carbamazepine using $\mathrm{Ti} / \mathrm{TiO}_{2}$ nanostructured electrodes deposited by means of a pulsed laser deposition process. Chemosphere 2013, 93, 2756-2766. [CrossRef] [PubMed]

38. Tran, N.; Drogui, P.; Zaviska, F.; Brar, S.K. Sonochemical degradation of the persistent pharmaceutical carbamazepine. J. Environ. Manag. 2013, 131, 25-32. [CrossRef] [PubMed] 